Afternoon Session

Chairman: J. H. WEIR EsQ., MD, BS, BHy, DPH, Medical Officer of Health, Kensington Borough Council, London, W8

\title{
The case for, and the work of, a community dietitian
}

By R. C. Wofinden, Medical Officer of Health, City and County of Bristol; Professor of Public Health, University of Bristol, and Margaret Chapman, Nutritionist, Department of Public Health, City and County of Bristol

At the Sixteenth English Meeting of The Nutrition Society, Dr C. F. Brockington, (Brockington, 1946) read a paper on The Dietitian in the Public Health Service. The war was over. Food rationing was still in force, but the brilliant national educational policy pursued by the Ministry of Food and a system of sound food priorities seemed to have played an important part in producing a healthier population than ever before in our history. The nation had, in fact, become diet-conscious and Brockington made a strong plea, "That the health departments of all major local authorities should have on their staffs an experienced dietitian' (a) to conduct dietary surveys of samples of the population and (b) to advise and educate health visitors (in his view the obvious field workers to give nutritional advice), housewives and the managers of hostels and nurseries.

Now 20 years later, has Brockington's dream been fulfilled?

Food rationing ended long ago; the standard of living for most sections of the population has improved beyond expectation: over- rather than under-nutrition seems to be the main problem; a silent revolution in the food industry and in the nation's feeding habits has led to the consumption of more and more sophisticated and out-of-season foodstuffs and to communal feeding on a large scale, and there is national concern about the long-term effects of ingesting small quantities of residual pesticides in foods or of antibiotics and hormones in milk and meat.

One might think that the need for a national educational policy was greater in consequence of these developments and that the role of the dietitian in society would have become more important. Yet, in I966, the number of local health authorities employing dietitians could be counted on the fingers of one hand. Why?

Public Health practice is essentially the large-scale application of scientific knowledge in the interests of the health of the public. After two decades of affluent living, with the widespread provision of welfare foods, milk and meals in schools, of factory canteen meals, of luncheon vouchers, of fortified flour and vitaminized foodstuffs, and of a welfare state geared to buttress us at all ages against the vicissitudes of life, are there no nutritional problems to be tackled? Certainly, it would appear from the evidence from the running indices on the Country's nutritional state-still-birth rate, neonatal death rate, rejection rate of female blood donors, standardized mortality rates for arteriosclerotic heart disease, serial measurements of heights and weights of schoolchildren, and from national food surveys-that there are no serious widespread problems for the nation as a whole. 
However, this broad approach may not throw enough light on the nutritional problems of population groups such as the aged or the immigrant or on groups living in particular geographical areas; even less does it throw light on the problems of individuals. Thus, in spite of the reassuring national picture Taylor (1967) states that chronic food deficiencies are widespread ... 'That many people in Britain do not have even the recommended low British levels' for vitamins; that vitamin and iron deficiencies are common in the aged and that in a sample of 600 army recruits $17.7 \%$ showed signs of old rickets. Dr Alex Comfort has also pointed out that, 'At present we don't have a diet that can prolong life. We do have a diet that shortens it. One misconception to straighten out is that old people need less protein than the young. If anything, they need more' and Maddison certainly seems to demonstrate the value of Complan (Glaxo Research Ltd) in improving the clinical condition of the aged at his Twickenham geriatric clinic. There is now also an increasing recognition of the nutritional problems to be faced in the immigrant population. As is well known, of all our habits, food habits are the longest established and one most difficult to change. So if traditional foods are not readily available in the country of adoption nutritional problems are almost bound to arise. These considerations and the enormous amount of misleading information advertising the value of special foods and health foods all point to the need for authoritative advice in dietary matters.

A big problem, however, is to decide what 'authoritative advice' can be given and who should give it. According to Browe (1959): 'Nutrition is more than diet. Nutrition also includes the digestion of nutrients and their absorption, transport to the tissues and utilisation by the cells' so its consideration involves very complex issues. In applied nutrition, there appear to be large gaps in our knowledge and varying interpretation of scientific data by our expert colleagues working in this field. There may be little doubt about the overt clinical symptoms and signs of undernutrition or of specific dietary deficiencies, but short of these we seem to get on to controversial ground. Is it known, for example, what is meant by 'optimal nutrition' or 'the physiological ideal' and how it can be measured? It must be a highly individual matter and small departures from the optimum difficult to detect and doubtful of significance. We compliment ourselves on the rising average heights and weights of schoolchildren in specific age groups over the past three or four decades and largely attribute this to better nutrition, but we do not really know the respective contributions to this result made by genetic, environmental or nutritional factors. We cannot even be certain apparently that this is going to lead to long-term health advantage for, according to Sinclair ( 1965$)$, 'We are causing children to mature earlier by increasing their calories (but) . . . we may be causing them to die earlier'.

A few years ago we were almost convinced that an important aetiological factor in the rising mortality from coronary artery disease was excessive intake of saturated fats. Middle-aged men were exhorted to switch from animal to vegetable and fish fats in their diet. Now we seem to be equally convinced that the increasing consumption of sucrose is the really important factor so the 'Coronary Club' patients in New York now eat diets in which both fat and sugar are restricted with an apparent reduction in the chances of further coronary episodes. According to a recent compilation 
(Kemp, 1967), 'Obesity is now showing itself in this Country not to be a problem of the isolated case, but rather a widespread tendency with serious morbidity connotations'. Yet, in spite of long-continued research it seems to be difficult to decide what, in fact, constitutes obesity, what are the aetiological factors (for to say that overeating causes obesity grossly oversimplifies the problem) and how it can best be prevented or, once established, successfully treated.

The presentation of even these brief facts illustrates some of the complexities involved and the rapidly changing picture in the field of nutrition. In this country, it is nearly always the mother who controls the pattern of the household diet. She is the one who, by being given advice and guidance, can do most to apply knowledge with the most widespread effect. It is mothers who are most readily accessible to health visitors, midwives and home nurses and it is, therefore, pertinent to ask whether these field workers are equipped to give advice.

Reid (1966) recently expressed the hope that the health visitor could be the main agency for giving practical dietary advice in the home. There can be little doubt that the tuition of the student nurse in hospital is insufficient to make her competent enough to give authoritative dietary advice in the public health field, and not very much more about nutrition (except for the expectant mother and infant) is taught in midwife training schools. Until about 3 years ago, the syllabus of training for the health visitor included specific tuition in nutrition, diet and budgeting. With the advent of the new syllabus these subjects were no longer specifically included. A recently addressed inquiry to Health Visitor Tutors (Wofinden, 1967, private inquiry), however, has disclosed that most schools are still giving active instruction in these matters (a tribute to the commonsense of the Tutors) although to such a varying extent that it is doubtful whether a qualified health visitor without still further training can be regarded as capable of giving more than very general advice. There does seem to be a case, therefore, for larger local health authorities to employ qualified dietitians if only to help with the in-service training of the health visitors.

There is a national shortage of dietitians and one wonders whether the rather restricted hospital role which she has traditionally performed lacks job-satisfaction. Hospital medical-social workers and psychiatric social workers are beginning to realize that the centre of gravity of health effort lies not in the hospital, but in the community which presents such interesting and challenging problems. With the prospect of a rapid rejuvenation of general medical practice through the establishment of health centres, careers in these vital para-medical fields could become both valuable and exciting.

In this country sufficient food is available for everyone to be adequately fed; nevertheless, malnutrition as manifest by, for example, obesity, anaemia, dental decay, still exists because essential nutrients are not taken in the correct proportion. This failure to eat the right foods for promoting good health often presents a greater problem than an overall insufficiency because it involves bringing the individual or the community to understand and accept the advantages of choosing one food rather than another. The work of a dietitian in a Department of Public Health is, therefore, 
directed towards promoting this better understanding of food values so that through wise choice and consumption of foods, nutritional standards are raised, thereby preventing disease and improving health.

A dietitian was first appointed to the staff of Bristol's Department of Public Health in 1949 and she was given the title of 'Nutritionist' to emphasize that her work would be concerned with the general nutritional welfare of all groups of the community rather than with therapeutic diets for a small sector of the population.

The work involves both direct and indirect service to individuals and groups of people. Routine work includes participating in the series of parentcraft classes arranged for antenatal patients. With a new group of approximately twelve people attending each of seventeen clinics every 6 weeks, a direct link is provided with about 1500 young people annually, each of whom will be intimately concerned in the feeding of at least two other people. The talk is on simple food values and is usually illustrated by slides and links the main function of food with the physiological needs of the baby and the mother. It is directed toward getting the mothers to know which are the important foods, the practical amounts of these to include in their daily diet; to take the Welfare Food and iron supplements and to realize the need for keeping their weight gain under control. As an extension of this, diet sheets for weight control in pregnancy have been made available to all doctors in the City and dietary advice and supervision is arranged for those who gain weight postnatally.

In connexion with the School Health Service, a clinic for overweight children has been established. The children are referred for dietary advice after they have had a medical examination as the confirmation of overweight and a doctor's recommendation to consult a dietitian are important in stimulating the mother to take action. The diet prescribed is for weight control in children rather than reduction and is kept as closely as possible to a normal well-balanced one, satisfying all nutritional needs apart from energy requirements. Thus, explanation of the dietary regime provides an opportunity for teaching food values and for showing how, by portion adjustment, it is suitable for the whole family, need not involve special cooking or draw attention to the individual-factors of importance as far as family catering is concerned. The children are seen at fortnightly intervals, if possible, by the dietitian, but if not, by a school nurse or health visitor during the term and by the dietitian during the holidays.

On an average there is a request from a Women's Group for a talk once a month by a dietitian. A title of, 'Food Facts and Fancies' allows scope for getting over important items of information; for disproving misconceptions and explaining changed opinions about food, and the information can be varied according to the type of audience. At all levels, these audiences provide a good medium for nutrition education as they form a nucleus of interested people who are not only willing to learn, but who are also willing to discuss and pass on the information they receive. Questions often suggest subject matter for future programmes. The help of Further Education staff and the Gas and Electricity Boards is enlisted if cookery demonstrations are wanted and, where appropriate, there is reciprocal participation in courses organized by these authorities. 
Talks are given to schoolchildren, sometimes in connexion with their normal human biology or home economics lessons or through taking part in programmes arranged by the Health Education Officer. In Bristol, the Nutritionist is a member of the Health Education staff and co-operates for any general Health Education programmes, but is free to plan her own schedule of work.

Each of the two Local Authority Health Centres in Bristol is visited for a $2 \frac{1}{2} \mathrm{~h}$ session once a fortnight. This enables the doctors who practise at the Centres to refer the patient direct to the Health Centre if dietary advice is needed. The vast majority referred are obesity patients who are then seen regularly at fortnightly intervals so that, in effect, obesity clinics have been established at these two Centres.

The Department has recently started a service providing a medical check-up for people at retirement age and in connexion with this, dietary advice and after-care supervision have been arranged for those showing nutritional defects. Where possible, these people are seen regularly by the dietitian as it is believed that sustained interest and after-care help to prevent apathy, so often a contributory cause of malnutrition among the elderly.

Contact is maintained with dietitians at local hospitals and, where necessary, follow-up of out-patients is arranged. Diet sheets have been prepared for one group of hospitals and, until a dietitian was appointed to the hospitals, the Public Health Nutritionist gave as much help as possible with patients, such as diabetics, needing more specialized dietary instructions and after-care. By serving on the Committee of the local branch of the Diabetic Association, a watching brief is maintained over many diabetics, a section of the community in which the relationships of diet and health are fairly obvious.

Some 18 months ago, a Diet Sheet Service for general practitioners was introduced whereby the Department of Public Health makes available, free of charge, supplies of reducing, gastric, low-fat and high-iron diet sheets, prepared by its Nutritionist. It was felt that such a scheme would help both doctor and patient and would also be a medium for nutrition education, particularly in the case of reducing diets, about which there is so much confused thinking. Participation in the scheme was optional and requests for initial supplies of the diet sheets were received from I 24 out of a possible 260 general practitioners. By the end of the ist year, replacement supplies for sixty-one pads of reducing, twenty-eight pads of gastric, seventeen of low-fat, diet sheets had been requested, but for only eight pads of the high-iron (each pad contains fifty copies of the diet sheet). A high usage of the low-fat diet sheets was not expected, but in view of the reported anaemia and the wide prescribing of medicinal iron there appears a need for people to increase their intake of dietary iron. Although a supplement is usually required to remedy anaemia once it is established, knowledge and the use of foods which provide iron and the realization that they can form the basis of attractive meals, could help to prevent the re-occurrence of this form of malnutrition. Persuasion of both doctors and patients to make fuller use of these diet sheets and/or investigation into their low usage will form part of the 'follow-up' treatment of the service.

Help and advice is given concerning menu planning and the kinds and quantities 
of foods to be included to cover nutritional requirements in Day Nurseries, Children's Homes, etc. and reports include those for the Mobile Meals Service, Old People's Homes and a small survey concerning children's breakfasts and what they ate at mid-morning break.

Guidance on nutritional matters is given to people, both trained and in-training, such as doctors, health visitors, social workers, home nurses, home helps and midwives working in the field of health or welfare who can play a significant part in spreading a greater knowledge of nutrition among the community. The Medical Officer of Health for Bristol is also Professor of Public Health at the University of Bristol and many courses are arranged jointly by the Department and the University.

Food and health are intimately related. Modern research is still bringing to light hitherto unknown and unexpected relationships. It has been said, 'People do not eat what they like, they like what they eat traditionally and each group has to teach its children in detail, how to like the particular foods on which they depend for sustenance'.

It is hoped that this account gives some idea of how a dietitian working in a Department of Public Health may further this.

\section{REFERENCES}

Brockington, C. F. (1946). Proc. Nutr. Soc. 4, 278.

Browe, J. H. (1959). In Preventive Medicine. [H. E. Hilleboe and G. W. Larimore, editors.] Philadelphia and London: W. B. Saunders.

Kemp, R. (1967). Medical News Magazine, January, p. 2.

Reid, J. J. A. (I g66). Nutrition, Lond. 20, 144.

Sinclair, H. M. ( (1965). Conf. Pap. R. Inst. publ. Hlth Hyg.

'Taylor, G. F. (1967). Medical Nezws Magazine, January, p. 10.

\section{An approach to the treatment of the obese schoolchild}

\section{By Phyldis M. Mortimer, Physician in charge of Weight Control Clinic, Public Health Department, Croydon}

There can be few medical topics that have received so much publicity in recent years as obesity and its treatment. Programmes have been devoted to the subject on radio and television, and women's magazines are constantly producing pages of helpful advice for the would-be slimmer.

With all this attention focused on a condition whose treatment (and serious consequences if left untreated) is well-known, an improvement in the incidence might have been predicted. Unfortunately, the converse is true and the percentage of overweight people in the populations of the USA and Great Britain is steadily rising. At present this is most clearly shown among adults but the increase in obesity in schoolchildren is considerable. In one secondary girls' school in Croydon an analysis of the heights and weights of the pupils in 1965 showed that, compared with Scott's (1955) figures for the London County Council in 1954 there was an increase of $5.9 \%-15.6 \%$ in mean weight, but only $1.98 \%-3.02 \%$ increase in mean height as shown by Table $\mathrm{I}$. 